\title{
Impacto das importações de bens no prêmio salarial nos polos-setores de TIC brasileiros
}

\author{
Gílson Geraldino Silva-Jr* \\ Hamilton José Mendes da Silva**
}

Resumo: Este artigo analisa o impacto das importações de bens no prêmio salarial para quatro setores TIC em cada um dos dez polos tecnológicos espalhados pelo Brasil, a partir dos dados da RAIS Migra-painel entre 2000-2009. Os principais resultados são: 1) há poucos profissionais de nível superior completo trabalhando nos polos-setores de TIC no Brasil; 2) os prêmios salariais são relativamente pequenos; 3) as importações reduzem estes já pequenos prêmios salariais. Concluímos que formuladores de políticas públicas precisam considerar o círculo vicioso de competição externa via importações de bens, prêmios salariais e presença de pessoal qualificado nos polos-setores de TIC no Brasil.

Palavras-chave: Prêmio salarial; TICs; Mão de obra qualificada.

Classificação JEL: J30; J31; C33.

\footnotetext{
* Doutor em Economia pela Universidade Federal do Rio Grande do Sul (UFRGS). Professor adjunto da Universidade Católica de Brasília (UCB). Endereço eletrônico: gilsongsj@gmail.com.

** Mestre em Economia pela Universidade Católica de Brasília (UCB). Membro da Secretaria de Política de Informática do Ministério da Ciência, Tecnologia e Inovação (MCTI). Endereço eletrônico: hamilton.mendes.silva@gmail.com. 


\section{Introdução}

As áreas associadas à tecnologia da informação e comunicação (TIC) são essenciais para a vida moderna. Estamos cercados de celulares, tablets e equipamentos médico-hospitalares cuja tecnologia é TIC. O desenvolvimento deste setor está intrinsecamente ligado à $P \& D \& I$, cujo insumo fundamental é mão de obra qualificada, engenheiros em particular. Porém, a insuficiência de mão de obra qualificada pode induzir a elevados níveis de importações, que podem ter impacto negativo nos prêmios salariais, criando um circulo vicioso nos polos-setores no Brasil: a pouca mão de obra qualificada formalmente empregada sofre competição externa via importações de bens, que por sua vez impacta negativamente no prêmio salarial nos polos-setores, reduzindo a atratividade remuneratória dos mesmos. Vejamos mais detalhes.

A OCDE destaca que a indústria de Tecnologia da Informação e Comunicação (TIC) nas duas últimas décadas do século passado tornou-se um dos impulsionadores da economia contemporânea, alcançando em 2006 valor de transações da ordem de US \$ 3,5 trilhões. Ainda segundo a Organização, TIC superou o faturamento da indústria automobilística e do setor petrolífero nos países com maior corrente de comércio, particularmente a China, país que assumiu a liderança na fabricação de bens de TIC, com produção de equipamentos eletrônicos que alcançou o valor de US\$ 413 bilhões em 2008 (OCDE, 2008).

Neste contexto, a mão de obra qualificada e os talentos para inovação são ativos estratégicos essenciais, pois sem eles não há inovação em alta tecnologia, como TICs. Conforme dados veiculados pela Secretaria de Política de Informática do MCTI (RDA, 2009), a indústria de TIC no Brasil empregou em 2009 cerca de 97 mil profissionais, dos quais 23 mil com nível superior, sendo que destes 6,7 mil atuam em pesquisa e desenvolvimento (P\&D). Em alguns segmentos o mercado brasileiro alcançou volumes expressivos, tornando-se o $3^{\circ}$ mercado mundial de microcomputadores, com comercialização de 14 milhões de unidades em 2010 (IDC Brasil, 2011) e 62 milhões de aparelhos telefônicos celulares (MCT, 2010).

Mas a importância das TICs não se resume à sua expressão econômica per se mas à sua característica singular de agregar valor aos mais diferentes setores econômicos, seja em serviços, na indústria de transformação ou no comércio, 
em suma perpassando literalmente quase que a totalidade das atividades da economia moderna.

Por outro lado, embora o Brasil já disponha de um parque produtivo relativamente diversificado, com empresas atuando nos mais importantes segmentos das TICs, como informática, automação e energia, telecomunicações e equipamentos médico-hospitalares, possui baixa capacidade de competição internacional, com as exportações respondendo por parcela inferior a $15 \%$ do faturamento setorial, sendo que o déficit anual da balança comercial de produtos eletroeletrônicos já ultrapassa US\$ 20 bilhões (ABINEE, 2010).

Uma das razões para esse desempenho modesto no mercado externo decorre do fato de que o país não tem demonstrado capacidade para concorrer com os custos do sudeste asiático, e o volume de recursos aplicado em P\&D e o contingente de recursos humanos alocados a tal atividade não tem viabilizado que o Brasil implemente com êxito uma estratégia de catch-up suficiente para alcançar os países líderes. Pelo contrário, as importações de equipamentos de TIC atigiu patamares significativos.

Conforme estudos divulgados pela ABDI (2009), uma das principais deficiências para inovar é a escassez de talentos para inovação, engenheiros em particular, numa proporção adequada a converter a indústria local num setor inovativo com o surgimento de empresas nacionais capazes de disputar a liderança, inclusive pela ocupação de espaço no mercado externo, em seus segmentos de atuação, replicando em TICs o que ocorreu no setor aeronáutico com a EMBRAER, que deslocou fornecedores tradicionais, respaldada principalmente em produtos inovadores, se tornando um global player.

Assim, é importante avaliar o contingente de profissionais mais qualificados da indústria brasileira de TIC, e identificar se essa indústria tem salários que a torna atrativa perante outros setores da economia.

Vale lembrar que TIC enquanto elemento catalisador do desenvolvimento econômico no contexto do atual paradigma tecnológico, e sua relação quase que simbiótica com a questão da inovação, foi definitivamente incorporado à agenda nacional da promoção da Pesquisa, Desenvolvimento e Inovação (P\&D\&I), por meio de sua inclusão entre os seis programas mobilizadores em áreas estratégicas da Política de Desenvolvimento Produtivo (PDP), lançada em 2008 (MDIC, 2011). 
A partir de dados da RAIS Migra-painel, montamos um painel de dados sobre número de pessoas formalmente empregradas com curso superior completo e prêmio salarial para os anos de 2000 a 2009 para os polos-setores de TIC, quais sejam, informática, energia e automação, telecomunicações e equipamentos médico-hospitalares, em Belo Horizonte, Campinas, Curitiba, Florianópolis, Ilhéus, Manaus, Porto Alegre, Santa Rita do Sapucaí, São Carlos e São Paulo. Informações complementares sobre importações de bens do setor foram obtidas da ABINEE e SECEX.

\section{Mão de obra qualificada e talentos para inovação nos polos-setores de TIC no Brasil}

A Tabela 1 ilustra o quão restrito é o contingente de talentos (engenheiros e profissionais correlatos) absorvido por essa indústria. Há, em média, 516 profissionais de nível superior nos polos-setores no período analisado, 67 engenheiros e 45 "outros talentos", como fisicos e analistas de sistemas.

Tabela 1 - Contingente de profissionais qualificados nos polos industriais de TIC

\begin{tabular}{l|c|c|c}
\hline \multicolumn{1}{c|}{ Categoria } & Média & DP & Máximo \\
\hline Profissionais com nível superior & 516 & 844 & 5.127 \\
Talentos Engenheiros & 67 & 124 & 769 \\
Talentos Não Engenheiros & 45 & 77 & 513 \\
\hline \multicolumn{2}{l}{ Fonte: Elaboração própria a partir de dados da base RAIS Migra. } \\
Total 400 observações.
\end{tabular}

Como regra, os profissionais qualificados nessa indústria são jovens com mais de $60 \%$ dos talentos e demais profissionais de nível superior situando-se nas faixas etárias de 25 a 39 anos - Tabelas 2 e 3.

Tabela 2 - Profissionais de nível superior por faixa etária

\begin{tabular}{lrrrr}
\hline Faixa etária & Média & \multicolumn{1}{c|}{ DP } & Máximo \\
\hline Profissionais de nível superior, faixa etária 18 a 24 & 29 & 48 & 402 \\
Profissionais de nível superior, faixa etária 25 a 29 & 108 & 165 & 979 \\
Profissionais de nível superior, faixa etária 30 a 39 & 203 & 328 & 1.858 \\
Profissionais de nível superior, faixa etária 40 a 49 & 125 & 217 & 1.262 \\
Profissionais de nível superior, faixa etária 50 a 64 & 50 & 102 & 763 \\
\hline Fonte: Elaboracão própria a partir de dados da base RAIS Migra
\end{tabular}


Tabela 3 - Talentos (engenheiros e não engenheiros) por faixa etária

\begin{tabular}{l|rrrr}
\hline Faixa etária & Média & \multicolumn{1}{c|}{ DP } & \multicolumn{1}{c}{ Máximo } \\
\hline Talentos (engs e não engs), faixa etária 18 a 24 & 10 & 17 & 115 \\
Talentos (engs e não engs), faixa etária 25 a 29 & 33 & 54 & 301 \\
Talentos (engs e não engs), faixa etária 30 a 39 & 42 & 75 & 450 \\
Talentos (engs e não engs), faixa etária 40 a 49 & 19 & 40 & 291 \\
Talentos (engs e não engs), faixa etária 50 a 64 & 5 & 14 & 120 \\
\hline
\end{tabular}

Fonte: Elaboração própria a partir de dados da base RAIS Migra. Total 400 observações.

\section{Prêmio salarial da mão de obra qualificada e talentos para inovação nos polos-setores de TIC no Brasil}

A Tabela 4 mostra que existe diferenciação salarial em favor dos engenheiros que atuam na indústria de TIC nos polos-setores selecionados relativamente ao salário médio pago no país aos profissionais de nível superior; assim como observa-se a existência de prêmio salarial desses engenheiros com relação aos profissionais de nível superior que atuam em outras atividades (incluindo Administração Pública) nessas mesmas localidades.

Vale destacar que o prêmio salarial dos talentos engenheiros é de cerca de 30\% (35\% relativamente ao salário médio nacional dos profissionais de nível superior e $31 \%$ relativamente aos profissionais de nível superior empregados em outras atividades dos polos-setores da base de dados).

Tabela 4 - Prêmio salarial dos talentos e profissionais de nível superior

\begin{tabular}{lrrrr}
\hline \multicolumn{1}{c}{ Categoria } & \multicolumn{1}{c|}{ Média } & Desvio-padrão & \multicolumn{1}{c}{ Máximo } \\
\hline WNSpolo/WNSBR & 1,04 & 0,22 & 1,55 \\
Wengpolo/WNSBR & 1,35 & 0,67 & 3,42 \\
Wnengpolo/WNSBR & 0,99 & 0,62 & 3,00 \\
Wengpolo/WNSpolo & 1,31 & 0,67 & 3,90 \\
Wnengpolo/WNSpolo & 0,93 & 0,55 & 3,54 \\
\hline
\end{tabular}

Fonte: Elaboração própria a partir de dados da base RAIS Migra. Total 400 observações.

Nota: WNSpolo é o salário do trabalhador com nível superior completo no polo-setor; WNSBR é o salário do trabalhador com nível superior no Brasil; Wengpolo é o salario dos engenheiros no polo-setor; Wnengpolo é o salário dos talentos não engenheiros no polo-setor.

Esse resultadoé consistente com o que foi obtido por Diaz-Chao (2008) que, em estudo empírico realizado na Espanha, apurou a existência naquele país de um prêmio de $34 \%$ em favor dos trabalhadores atuando em indústrias intensivas em conhecimento, com ênfase no contingente de trabalhadores que exercem atividades com elevado emprego de ferramentas e recursos computacionais caso dos profissionais que exercem atividades de P\&D na indústria de TIC. 
Curiosamente, não há diferenciação salarial em favor dos profissionais da categoria talentos mas que não são engenheiros, o que não deixa de ser surpreendente já que esse grupo inclui profissionais de informática que atuam no desenvolvimento de programas de computador (como por exemplo, os analistas de sistemas e cientistas da computação), cuja escassez também vêm sendo apontada em estudos e na própria mídia especializada (Revista TIC Mercado, 16 de março de 2011).

É possível que a escassez seja não tanto de profissionais graduados mas sim de profissionais com a qualificação demandada pelo setor empresarial, de forma que muitos dos profissionais absorvidos iniciam com salários mais reduzidos, mas por outro lado exigem um maior investimento para complementar sua formação.

\section{Importações de bens e seus impactos sobre a mão de obra qualificada e talentos para inovação nos polos-setores de TIC no Brasil}

Com relação às importações de bens, a Tabela 5 mostra que a indústria brasileira de TIC possui um elevado coeficiente. Esse resultado é coerente com o comportamento da balança comercial do setor, cujo déficit em 2010 já alcançou a cifra de US\$ 10 bilhões conforme dados divulgados pela ABINEE e SECEX.

Tabela 5 - Importações em relação ao faturamento, por segmento, da indústria de TIC (\%)

\begin{tabular}{c|c|c|c|c}
\hline Variável & Média & $\begin{array}{c}\text { Desvio- } \\
\text { padrão }\end{array}$ & Mínimo & Máximo \\
\hline Importações/faturamento & 56 & 47 & 10 & 188 \\
\hline
\end{tabular}

Fonte: Elaboração própria, a partir de dados da ABINEE e da ABIMO.

As regressões em painel com efeitos fixos para polo-setor para o período 2000-2009 (Tabela 6) mostram que as importações de bens reduzem os prêmios salariais, com exceção do prêmio salarial do profissional de nível superior formalmente empregado nos polos-setores em relação ao profissional de nível superior formalmente empregado em qualquer setor ou cidade. 
Tabela 6 - Impacto das importações sobre o prêmio salarial dos talentos e profissionais de nível superior nos polos-setores TIC

\begin{tabular}{l|r|r|r|r|r}
\hline & $\begin{array}{c}\text { WNSpolo- } \\
\text { WNSBR }\end{array}$ & $\begin{array}{c}\text { Wengpolo- } \\
\text { WNSBR }\end{array}$ & $\begin{array}{c}\text { Wnengpolo- } \\
\text { WNSBR }\end{array}$ & $\begin{array}{c}\text { Wengpolo- } \\
\text { WNSpolo }\end{array}$ & $\begin{array}{c}\text { Wnengpolo- } \\
\text { WNSpolo }\end{array}$ \\
\hline Cte & $1,05^{* * *}$ & $1,49^{* * *}$ & $0,44^{* * *}$ & $1,44^{* * *}$ & $1,14^{* * * *}$ \\
Import & $-0,18$ & $-0,24^{* *}$ & $-0,24^{* * *}$ & $-0,23^{*}$ & $-0,38^{* *}$ \\
\hline
\end{tabular}

Fonte: Elaboração própria a partir de dados da base RAIS Migra. Total 400 observações.

Nota: WNSpolo é o salários do trabalhador com nível superior completo no polo-setor. WNSBR é o salário do trabalhador com nível superior no Brasil. Wengpolo é o salario dos engenheiros no polo-setor. E Wnengpolo é o salário dos talentos não engenheiros no polosetor. *,**,*** indicam, respectivamnte, significância estatística a $10 \%, 5 \%$ e $1 \%$.

Ou seja, de fato procede a suspeita de que a insuficiência de mão de obra qualificada pode induzir a elevados níveis de importações, que podem ter impacto negativo nos prêmios salariais, criando um circulo vicioso nos polos-setores no Brasil: a pouca mão de obra qualificada que existe sofre competição externa via importações de bens, que por sua vez impacta negativamente no prêmio salarial deste setor, reduzindo a atratividade remuneratória do mesmo.

\section{Conclusões}

A análise das informações que obtivemos para o período 2000-2009 para 4 setores TIC em cada um dos 10 polos tecnológicos espalhados pelo Brasil permitem concluir que: 1) há poucos profissionais de nível superior completo trabalhando nos polos-setores de TIC no Brasil; 2) os prêmios salariais são relativamente pequenos; 3) as importações reduzem estes já pequenos prêmios salariais. Formuladores de políticas públicas precisam considerar o circulo vicioso de competição externa via importações de bens, prêmios salariais e presença de pessoal qualificado nos polos-setores de TIC no Brasil.

\section{Referências}

Agência Brasileira de Desenvolvimento Industrial. "Talentos para inovação na indústria: experiências internacionais". URL [on-line]: http://www.abdi.com. br/Estudo/Talentosparainovacao.pdf. Acesso em: 10 de novembro de 2010.

Associação Brasileira da Indústria de Artigos e Equipamentos Médicos, Odontológicos, Hospitalares e de Laboratórios. URL [on-line]: http://www.abimo. org.br.

Associação Brasileira da Indústria Elétrica e Eletrônica. URL [on-line]: http://www. abinee.org.br. 
Díaz-Chao, A. (2008). "Las diferencias salariales en la economia del conocimiento: um análisis empírico para España”. Revista sobre la Sociedad del Conocimiento 6.

Gomes, Marinês. (2011). "Para driblar apagão de mão de obra, empresas de TI investem em capacitação dentro de suas instalações e junto às universidades e escolas técnicas". Revista TIC Mercado. URL [on-line]: http://www.ticmercado. com.br/ticmercado.php?edi=96\&tabs=tab3. Acesso em: 22 de julho de 2011.

Ministério da Ciência e Tecnologia. (2009). Relatório Estatístico - RDA 2009. URL [online]: http://sigplani.mct.gov.br. Acesso em: 25 de julho de 2011.

Ministério do Desenvolvimento, Indústria e Comércio Exterior. Política de Desenvolvimento Produtivo (PDP). URL [on-line]: http://www.pdp.gov.br. Acesso em: 27 de julho de 2011.

Ministério do Trabalho e Emprego. Bases Estatísticas Rais/Caged. URL [on-line]: http: //sgt.caged.gov.br.

Silva, H. J. M. (2010). Determinantes dos diferenciais de salários entre profissionais qualificados para inovar na indústria brasileira de tecnologia da informação e comunicação. Brasília: dissertação de mestrado, Universidade Católica de Brasília. 